\title{
AS INÚMERAS ROTAS EM “NUNCA MAIS" DE EDYR PROENÇA
} Antônio Daniel FÉLIXI Wellingson Valente Dos REIS ${ }^{2}$

\begin{abstract}
RESUMO
Este trabalho tem por finalidade fazer uma análise de como ocorre a relação entre as estruturas narrativas do texto literário, isto é, a relação entre uma dada ação narrativa que conduz o leitor a criação de um horizonte, que pode ou não ser, pelas ações futuras, preenchido ou confirmado. Sendo que esse horizonte, ao tornar-se noutra ação, gera outro horizonte, dando, assim, continuidade ao desenrolar da narrativa. De qualquer forma, essa relação entre as ações sofre influências do eixo temporal que, por sua vez, funciona como base para que essa relação seja possível, organizando, por sua vez, a coerência ou aquilo que dará sentido à obra. A partir desses pressupostos analisaremos a multiplicidade de interpretações cabíveis, que podem ser criadas como horizonte, tendo a obra literária como de natureza perspectivística, no conto Nunca mais de Edyr Proença, com a finalidade de se chegar, ao final do conto, à melhor interpretação possível em relação ao personagem Dico. Para tanto, partiremos dos pressupostos dos estudos de, principalmente, Iser (1996) e Bakhtin (2015) entre outros.
\end{abstract}

Palavras-chave: Edyr Proença. Multiplicidade interpretativa. Nunca mais.

\section{RESUMEN}

Este trabajo tiene por finalidad hacer un análisis de cómo ocurre la relación entre las estructuras narrativas del texto literario, es decir, la relación entre una determinada acción narrativa que conduce al lector a la creación de un horizonte, que puede o no ser, por las acciones futuras, cumplimentado o confirmado. Siendo que ese horizonte, al tornarse en otra acción, genera otro horizonte, dando así la continuidad al desarrollo de la narrativa. De cualquier forma, esa relación entre las acciones sufre influencias del eje temporal que, a su vez, funciona como base para que esa relación sea posible, organizando, a su vez, la coherencia o aquello que dará sentido a la obra. A partir de estos presupuestos analizaremos la multiplicidad de interpretaciones cabales, que pueden ser creadas como horizonte, teniendo la obra literaria como de naturaleza perspectivística, en el cuento "Nunca mais" de Edyr Proença, con la finalidad de llegar, al final del cuento, la mejor interpretación posible en relación al personaje Dico. Para tanto, partiremos de los presupuestos de los estudios de, principalmente, Iser (1996) y Bakhtin (2015) entre otros

Palabras-llave: Edyr Proença. Multiplicidad interpretativa. Nunca mais

\footnotetext{
1 Graduando em Licenciatura em Letras - Língua Portuguesa pelo Instituto Federal de Educação, Ciência e Tecnologia do Pará - IFPA. E-mail: antodanfel@outlook.com.
}

2 Doutorando em Comunicação, Linguagens e Cultura pela Universidade da Amazônia (UNAMA). Bolsista PROSUP/CAPES; Mestre em Comunicação, Linguagens e Cultura (UNAMA). Membro do Grupo Interdisciplinar de Pesquisa em
Arte, Cultura e Educação (GIPACE/ IFPA/CNPQ) e do Grupo de Pesquisa Interfaces do Texto Amazônico (GITA/ UNAMA). E-mail: wellingsonreis@uol.com.br.
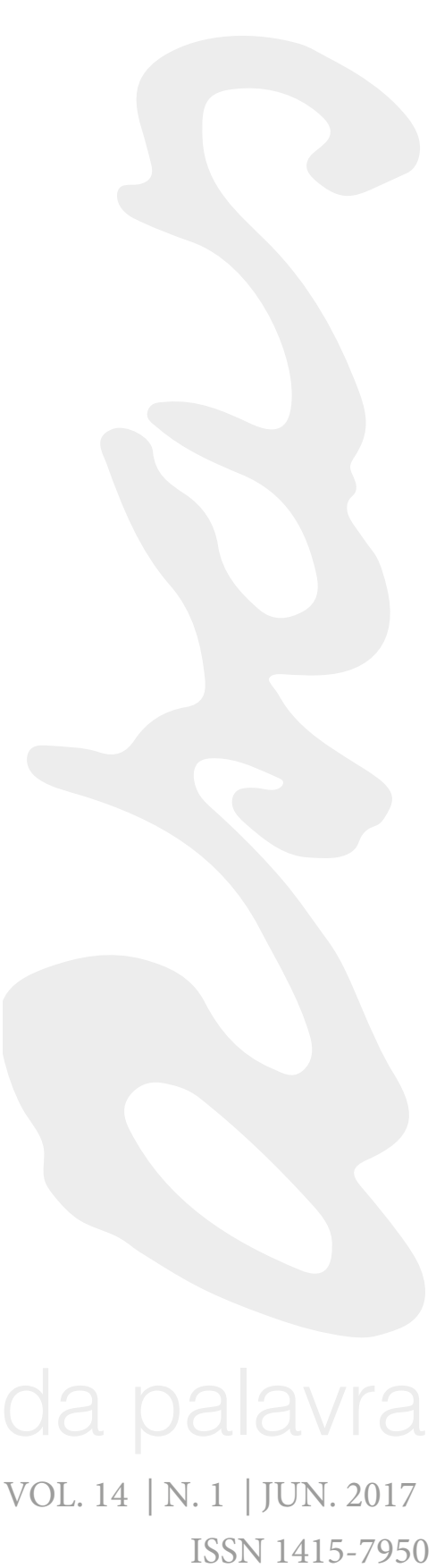


\section{CONSIDERAÇÕES INICIAIS}

Ao analisar uma obra literária todos concordam que uma obra literária possui inúmeras possibilidades de interpretação, sendo essas interpretações "controladas" pelo autor, que escreveu o texto, ou seja, o texto torna-se uma espécie de "guia" para o leitor, uma vez que, como afirma Eco (2015):

As sugestões são voluntárias, estimuladas, explicitamente evocadas, mas dentro dos limites preestabelecidos pelo autor, ou, melhor, pela máquina estética que ele pôs em movimento. A máquina estética não ignora as capacidades pessoais de reação dos espectadores, pelo contrário, chama-as à ação e converte-as em condição necessária para sua subsistência e para seu sucesso; mas orienta-as e domina-as. (ECO, 2015, p. 113).

Devido a obra literária ser de natureza perspectivística, isto é, possuir inúmeros pontos de vista que, ao se relacionarem, entrarão em conflito, conflitos esses que darão prosseguimento à obra, durante a leitura, segundo Iser (1996), um leitor nunca preencherá toda a narrativa, pois ele assumirá um ponto de vista, isto é, identificar-se-á com um personagem, incluindo aí o narrador, e daí atribuirá valor à obra ou não, sendo que o sentido, como diz Iser (1996), é construído gradualmente, de modo que ao final, e somente ao final, como também defende Bakhtin (2011, p. 4), é que se chega ao sentido da obra, vendo-a como um todo, valorizando-a ou desvalorizando-a, o que depende do que acontecerá com o personagem com o qual identificou-se o leitor. Uma vez que:

Como queremos captar a estrutura subjacente ao ponto de vista do leitor, acreditamos serem dignas de reflexão mais profunda as observações de G. Poulet sobre a leitura. Os livros, diz ele, só no leitor ganham plena existência. Embora eles desenvolvam os pensamentos de outrem, o leitor se transforma durante a leitura em sujeito desses pensamentos. Desse modo desaparece a cisão entre sujeito e objeto, cisão essa que é tão importante para o conhecimento e a percepção em geral. Daí se pode concluir que é a suspensão dessa divisão que faz da leitura uma categoria especial, a qual permite o acesso a possiveis experiencias num mundo não-familiar. Tal "fusão" singular explica também o mal-entendido causado pela ideia de ser a relação entre texto e leitor uma relação de identificação. (ISER, 1996, p. 85)

Bakhtin (2015) tem um ponto de vista semelhante ao de Iser (1996) acrescentando que, além dessa "compenetração" (Bakhtin, 2015, p. 23) como fala o autor, isto é, a fusão entre o leitor e o personagem, "A atividade estética começa propriamente quando retornamos e damos acabamento ao material compenetrado" (Bakhtin, 2015, p. 25). Assim, a partir desses pensamentos, podemos dizer que, uma vez que o leitor se funde com o personagem, ambos sofrem as ações, logo, o sofrimento do personagem é o sofrimento do leitor, o que pode implicar na valorização da obra pelo leitor. Em outras palavras, se o leitor passar por "boas aventuras", provavelmente ele se importará mais com a obra, em detrimento de outra que não o deu tanto "prazer".

Para esta nossa análise, escolhemos o personagem Dico, no entanto analisaremos os demais, uns em relação aos outros, de modo que ao final possamos chegar em possíveis leituras do texto. Como assumiremos um ponto de vista, o do personagem Dico, nossa análise em relação aos outros talvez não seja tão satisfatória, até porque não é esse nosso objetivo. Vale ressaltar que tentaremos fazer uma análise 
possibilidades de leituras do personagem.

\section{NUNCA MAIS}

Nunca mais é um "mini conto", como diz Schollhammer (2009, p. 14), de apenas uma página e meia, aproximadamente, dividido em, basicamente, oito ações, narra a estória de Dico, que, por relacionar-se com a mulher de um provável traficante, é perseguido por ele e seus parceiros e já estando ferido vai para o Ver-o-peso que é sua morada, visto que ele mora na rua, rouba turistas e "queima pasta".

A fim de escapar das pessoas que o perseguem, sempre pensando em sua amada Lelê, Dico esconde-se em um canto, onde encontra alguns colegas que vão embora deixando-lhe tinner. Ele fica lá, na espera de ir embora escondido em um barco. Enquanto espera a chegada dos barcos, bem como do amanhecer, Dico, em meio a ratos e junto a um urubu que come carniça, pede que o urubu divida sua "comida" com ele, no entanto esse urubu the responde uma única coisa "nunca mais". Dico pensa em Lelê mais uma vez, algo se aproxima e ele só ouve "nunca mais, nunca mais".

Ao final do conto, temos a indefinição como marca da narrativa, pois não sabemos se Dico é finalmente encontrado por aqueles que o perseguiam para matá-lo ou se ele caiu no chão dopado por sua mistura de tinner e pasta, que ele "queimava". Iser (1996) diz que a obra literária é de natureza perspectivística, embora haja uma perspectiva dominante, que é o ponto de vista do personagem principal, no caso do mini conto a perspectiva de Dico é a que prevalece na narrativa, mesmo o conto contando com outros personagens como: os amigos de Dico que lhe dão tinner, Lelê, Fera e o narrador.

Os amigos de Dico, são covardes, pois, com medo de Fera, abandonam-no à sorte. Por isso, eles têm uma única aparição ao longo do conto. Fera e Lelê, não aparecem no conto, isto é, não possuem nenhuma fala, mas estão bastante presentes na narrativa, por meio do pensamento de Dico, o personagem principal.

Em se tratando do narrador, ele tem apenas uma aparição ao longo do conto, visto que esse conto tem características contemporâneas, logo, como diz Schollhammer (2009, p. 14-15) "O uso das formas breves, a adaptação de uma linguagem curta e fragmentária e o namoro com a crônica são apenas algumas expressões da urgência de falar sobre e com o 'real"'. Na tentativa de aproximar-se do real, o conto traz em si uma linguagem bem corrida, sem separação, o que as vezes dificulta a leitura, pois ficamos na dúvida sobre qual personagem está falando, o que requer uma atenção maior do leitor.

\section{PROENÇA, EM BUSCA DE UMA ESSÊNCIA}

De acordo com o site da Boitempo Editorial

Edyr Augusto é um escritor e jornalista paraense, vencedor do prêmio Caméléon. Nascido em Belém, em 1954, inicia sua carreira como dramaturgo no final dos anos 1970. Escritor e diretor de teatro, Edyr trabalhou como radialista, redator publicitário, autor de jingles além de produzir poesia e crônicas. sua estreia como romancista se dá em 1998, com a publicação de Os éguas. Quadro desolador da metrópole amazonense, o "thriller regionalista" mergulha no ritmo frenético da decadência e da violência urbana.

Muito apegado à sua região do Pará, Edyr Augusto ancora lá todas as suas narrativas. [...] conhecidos por representarem o que há de mais interessante na literatura contemporânea paraense, mas com temas identificáveis em qualquer cenário 
urbano. Sua linguagem é coloquial, típica da região, compondo um retrato perfeito da oralidade local. A temática urbana, com uma trama de suspense que se desenrola por bares, botecos, restaurantes, delegacias, clubes e motéis, ecoa a tradição policialesca noir. É nesse encontro que se configura o estilo singular da obra de Edyr Augusto.

Nessa tentativa de levar o real para a obra literária, o autor acaba, de certa forma, "matando" o narrador ou ocultando-o. Isso é bem visto no "mini conto" aqui analisado. $\mathrm{O}$ autor, enquanto cria sua obra, sua perspectiva, assim como a do leitor enquanto a lê, é unívoca, isto é, ele não ver os personagens enquanto todos, mas apenas um de cada vez, ou seja, nas palavras de Bakhtin

o autor cria, mas vê sua criação apenas no objeto que ele enforma, isto é, vê dessa criação apenas o produto em formação e não o processo interno psicologicamente determinado. [...] vivencia-se o trabalho criador, mas o vivenciamento não escuta nem vê a si mesmo, escuta e vê tão somente o produto que está sendo criado ou o objeto que ele visa. (BAKHTIN, 2014, p. 5).

Daí que Iser (1996) e Zilberman (2001) concordam com o pensamento de Proust, que é citado pelo próprio Iser (1996) de que quando lemos libertamo-nos de nós mesmo e incorporamos o outro, ou como diz a própria Zilberman (2001, p. 53) "Se ler é pensar o pensamento de outros, é igualmente abandonar a própria segurança para ingressar em outros modos de ser, refletir e atuar. É, por fim, apreender não apenas a respeito do que está lendo, mas, principalmente, sobre si mesmo".

Por isso que Bakhtin (2014, p. 4-5) diz que "A luta do artista por uma imagem definida da personagem é, em um grau considerável, uma luta dele consigo mesmo.".

Portanto, tanto o autor quanto sua criação, durante sua "passagem pela vida" são variáveis, podendo ser amado ou odiado apenas ao final de seu percurso. Uma vez que a essência do ser se encontra no todo, não em partes suas. Como vimos, as partes inter-relacionam-se em constante configuração uma da outra.

\section{A VIDA DE DICO}

Passaremos para a análise das possíveis leituras que podem ser feitas do conto, visualizando as lacunas deixadas pelo autor, Edyr Proença, e as possíveis formas de preencher essas lacunas pelos leitores.

Na primeira ação da narrativa, há a descrição de uma fuga, sem qualquer explicitação de que ou quem estaria em fuga, o que nos permite perceber a primeira lacuna deixada pelo autor. Em se tratando dessas lacunas, Zilberman (2001) afirma que

Numa obra de ficção, personagens, coisas, sentimentos, espaço e até o tempo aparecem de forma inacabada e descontínua, exigindo necessariamente a intervenção do leitor. Ele completa as lacunas colocadas pelo texto, tornando-se co-participante do ato de criação." (ZILBERMAN, 2001, p. 51).

Logo, temos a possibilidade de criação de dois horizontes:

1. Seria um animal que estaria sendo caçado?

2. Seria uma pessoa que estaria fugindo de alguma coisa ou de alguém? 
que:

como as perspectivas do texto se originam de diversos pontos de vista, elas precisam ser relacionadas entre si, [...]. Por isso as perspectivas do narrador, dos personagens, da ação e da ficção do leitor - apesar de sua estrutura diferente - não pode separar-se, se bem que suas divergências sejam muitas vezes evidentes. Para isso dão necessárias operações que permitem a coordenação das diversas perspectivas. A estrutura de tema e horizonte cumpre essa função. Ela regula primeiro as atitudes do leitor em relação ao texto, cujas perspectivas de separação não se desenvolvem nem sucessivamente, nem paralelamente, mas sim se entrelaça no texto. Por isso, o leitor não é capaz de abarcar todas as perspectivas ao mesmo tempo, senão que, durante o processo da leitura, ele toca nos diversos segmentos das perspectivas diferentes de representação. (ISER, 2006, p. 180- 181).

Em outras palavras, podemos dizer que uma dada ação permite-nos imaginar/criar horizontes sobre seu estado e/ou efeito futuros. Em relação ao fato de a obra ser de natureza perspectivística, dependendo da experiência de vida do leitor, ele pode assumir/identificar-se com a perspectiva do personagem que caça ou o que está sendo caçado. Definindo, portanto, seu ponto de vista a ser usado como base para sua interpretação, no entanto, vale ressaltar que “[...] as interpretações são paralelas, de modo que uma exclui as outras, sem, contudo, negá-las. " (PAREYSON apud ECO, 2015, p. 95)

Mais adiante um de nossos horizontes é confirmado, chegamos à conclusão de que se trata de um animal, uma vez que na seguinte passagem "Deixo um rastro de sangue que facilita minha caça" (PROENÇA, 2015, p. 158) o que poderíamos atribuir à caça de animais, mas o que não faz muito sentido, pois sabemos que caça aos animais não se faz, nem por "esporte" na cidade, porém, de qualquer forma, já temos a certeza de que há uma perseguição e que alguém ou algum animal está ferido.

$\mathrm{Na}$ segunda ação nossa incerteza do que se trataria a primeira ação é definida pela seguinte passagem "Molhamos a mão dos guardas" (PROENÇA, 2015, p. 158), uma vez que sabemos que tal ação de suborno é executada pelos seres humanos. Além disso, sabemos que animais não roubam turistas. O que fica claro na passagem em que Dico diz "Roubamos turistas." (PROENÇA, 2015, p. 158). Em relação ao ato de interpretar ou atribuir sentido à obra, não poderíamos fazê-lo senão a partir de nosso conhecimento de mundo ou experiencia de vida, pois:

[...] a obra que surge não se apresenta como novidade absoluta num espaço vazio, mas, por intermédio de avisos, sinais visíveis e invisíveis, traços familiares ou indicações implícitas [...] Ela desperta a lembrança do já lido, enseja logo de início expectativas quanto a "meio e fim" (JAUSS, 1994, p. 28)

Somente com base em nossa experiencia de vida que podemos interpretar tanto a obra quanto a própria vida, por isso percebemos que o autor narra a caça do animal homem, na cidade, ou seja, o autor usa mão do recurso da comparação para criar sua narrativa, e o leitor com o seu conhecimento de mundo deve preencher essa lacuna, para perceber que a caça na verdade é uma perseguição, que se assemelha a uma caça, pois um está armado tentado matar o outro que foge como um animal.

Aqui, sentimos a necessidade de abrirmos um parágrafo para tratarmos da penúltima expressão. Para uma pessoa que desconheça o contexto linguístico social ao qual a estória faz referência, provavelmente sentirá certa dificuldade em atribuir sentido a passagem na qual ela está. Bakhtin (2011, p. 261-262), ao falar dos gêneros do discurso, diz que cada gênero traz em si características linguísticas da comunida- 
de de sua origem. Ferrazi Junior (2008, p. 26), ao falar da semântica de contextos e cenários, afirma que:

A primeira coisa que precisamos compreender é que nenhum sinal tem sentido próprio. Não há sentido literal nas línguas naturais, pelo menos não como tradicionalmente entendemos a expressão "sentido literal". [...] Nenhuma palavra tem um sentido próprio, que seja só dela e sempre associado a ela. Nenhum mesmo. (FERRAZI JUNIOR, 2008, p. 26).

Nesse caso, alguém poderia imaginar que a palavra "molhar a mão" realmente significaria "jogar água sobre a mão", no entanto, não seria essa a melhor interpretação, uma vez que o que o texto traz nessa expressão, como toda, é uma indeterminação ou um convite ao "preenchimento" do sentido, como diria Iser (1996, p. 57-58) e Zilberman (2001, p. 51), ou indícios paradigmáticos, como diria Todorov (2014, p. 34-35), para quem a obra pode relacionar-se consigo mesma, explicitando/ necessitando de seus indícios sintagmáticos, ou com o mundo, explicitando/necessitando de seus indícios paradigmáticos. De qualquer forma, acreditamos que a melhor interpretação a essa expressão seja o suborno, isto é, o fato de infratores darem dinheiro aos guardas para não serem detidos, por causa de uma ou outra vez que são pegos, seja por roubo ou qualquer outra coisa.

O certo é que algumas situações seguem uma lógica mais aberta, em quanto outras dificilmente terão uma dupla possibilidade de leitura, por isso concordamos com Compagnon (2010, p. 67), quando este afirma que "[...] um texto tem tantos sentidos quanto leitores, $\mathrm{e}[\ldots]$ não há como estabelecer a validade (nem a invalidade) de uma interpretação", sendo que, claramente, como diz Iser (1996), as interpretações são guiadas pela obra, mas, juntando ambas as concepções, concordamos com Culler (2011, p. 69) que diz que a obra literária não se reduz apenas a uma ou outra propriedade de seu texto nem à experiência de um sujeito, mas, sim, a ambas simultaneamente. Acreditamos ser válido dizer que, ainda de acordo com Culler (2011, p. 70), "O sentido está preso ao contexto, mas o contexto é ilimitado". Para fazermo-nos mais claros, citamos Compagnon (2010, p. 141), para quem "A leitura tem a ver com empatia, projeção, identificação. Ela maltrata obrigatoriamente o livro, adapta-o às preocupações do leitor. [...] o leitor aplica o que ele lê à sua própria situação", isto é, em nossa concepção, embora a leitura seja guiada pelo texto, a atribuição de sentido ao texto dar-se por meio do conhecimento prévio, como diria Jauss (1994), de cada leitor, sendo assim, a ação adaptada ao contexto do leitor. Logo, nossa interpretação, assim como nenhuma outra, não deve ser tomada como dogmática.

Na terceira ação, temos a impressão de que os amigos de Dico o ajudariam, no entanto, mais uma vez, esse horizonte é quebrado, na seguinte passagem, quando seus amigos o abandonam: "Melhor dar no pé" (PROENÇA, 2015, p. 158). Na quarta ação, sentimos a aflição na qual encontra-se o personagem, escondido em meio a ratos e na presença de um urubu que chega com um pedaço de carniça. Na espera da chegada dos barcos com açaí, onde pretende se esconder, em um dos barcos, e, enfim, conseguir fugir.

Na quinta ação, Dico pensa em sua amada, nos momentos em que, quando estava com seu parceiro, chamado de Fera e que, provavelmente, seria um traficante, "dava-lhe mole", isto é, transparecia-lhe que queria trair seu parceiro com ele. Além disso, pensa nos bons momentos em que esteve com ela, na praia, na Curuzu, etc.

$\mathrm{Na}$ sexta ação, surge o narrador, que até este momento estava fora da narrativa. Ademais, há um diálogo em que Dico tenta convencer o urubu a dividir sua carniça com ele que, provavelmente, está faminto. Não obstante, o urubu só lhe responde "Nunca mais". (PROENÇA, 2015, p. 159)

Na sétima ação, o personagem pensa em sua amada que nunca mais verá, ainda pede ao urubu que divida sua carniça com ele, pois em breve o urubu comerá os seus olhos, uma vez que Dico está aflito e acredita que seu fim está próximo, isso 
mais. Lelê, meu amor que nunca mais verei" (PROENÇA, 2015, p. 159)

Na oitava e última ação, há a chegada de alguém, e nesse momento o personagem fica apavorado, pois está tudo escuro. Dico chama por Lelê na expectativa de que seja ela que esteja chegando. Fala ao urubu que ele já ficará com seus olhos. Daí não fala mais nada e só ouve “"nunca mais, nunca mais” (PROENÇA, 2015, p. 159).

Como dito anteriormente, Bakhtin (2011, p. 4) defende que uma narrativa deve ser analisada em sua integridade, de modo que não haja equívocos, enquanto que Jauss (1994) e Iser (1996) apesar de concordarem com a ideia de que a narrativa deve ser analisada em sua integridade, defendem também que a obra se constrói aos poucos e que, portanto, é lida e interpretada gradualmente, logo, sua análise também é de cunho gradual. Sendo que durante a "construção" da narrativa há uma construção e uma desconstrução ou confirmação ou não de certas ações, que Iser (1996) chama de estruturas de tema e horizonte enquanto que Jauss (1994) chama de horizonte de expectativas. Essas construções e/ou desconstruções de ações, podemos perceber na análise ao longo das oito ações principais presentes no conto. Ademais, percebemos que elas se sobrepõem, isto é, que há a constante relação entre as ações passadas, presentes e futuras, ou seja, uma relação entre as ações num eixo temporal que as organiza de tal modo a garantir a coerência do texto, ao final, como um todo. Em relação a esse eixo temporal, Iser (1996) fala sobre sua importância afirmando que:

A sequência da representação é condicionada principalmente pela duração temporal da leitura. Em vista de sua duração, a leitura produz um eixo temporal, em que os objetos imaginários criados pela representação se reúnem, criando uma ordem sucessiva. Confluem, portanto, no eixo temporal todos os produtos da representação, por mais contraditórios e heterogêneos que sejam. A sucessão temporal permite que percebamos diferenças, contrates e oposições entre os objetos da representação, gerados durante o processo de leitura. O eixo temporal recebe assim a sua estruturação e os objetos imaginários ganham sua identidade quando são distinguidos um do outro. $O$ fator temporal evidencia a diferença que reina entre os objetos da representação; e essa diferença estimula por sua vez o leitor a inter-relacionar os objetos durante a leitura. (ISER, 1996, $p$. 76)

A partir desses pressupostos, podemos dizer que, apesar de não haver qualquer índice no conto em relação à infância, juventude de Dico, nem sequer de qualquer parente. Podemos perceber ao longo do conto que esse personagem, além de ser um provável morador de rua, pois ele diz que o Ver-o-peso é a sua casa, comete pequenos roubos e que, por algum motivo, é respeitado por Fera, o companheiro de Lelê, pela qual Dico é apaixonado. Sendo Fera um personagem que, como relata-se no conto, "não dispensa" (PROENÇA, 2015, p. 158), isto é, se tem algum problema com alguém, ele não hesita em cometer homicídio. Dico, por ser respeitado por Fera, provavelmente, sente-se no poder de tomar sua parceira.

O fato de Dico não ter desistido de Lelê, quando o parceiro dela pediu, implica no de ele "ser forçado" a matá-lo, ou simplesmente, ordenar que o matem. Tudo indica, nas últimas ações do conto, que o personagem planejava fugir da morte, mas que não desistiria de sua amada e que, logo, voltaria para buscá-la.

Assim, ao final do conto, temos outras lacunas para que o leitor preencha, dentro das possibilidades de leituras percebemos três possíveis interpretações, o que não exclui outras interpretações:

1. Dico, por estar ferido e bastante drogado, ouvindo ou simplesmente tendo a alucinação de ouvir o urubu falar "nunca mais" apaga, isto é, dorme.

2. Dico é surpreendido com a aparição de Lelê dizendo que nunca mais 
ficaria separada dele, no entanto, o conto terminaria antes de ela concluir sua fala, dando um ar de suspense ao final do conto e, assim, deixando-o em aberto.

3.CDico é realmente surpreendido por Fera e/ou seus subordinados que o matam, fazendo com que ele "nunca mais" fique com a Lelê.

Dentre essas três possibilidades de leitura, ou outras, é que o leitor real poderá transitar para a sua interpretação do conto, mostrando que mesmo com uma leitura total do conto, o mesmo permanece como um conto de múltiplas interpretações, nas quais os leitores se apoiariam para interpretarem esse final.

\section{CONSIDERAÇ̃̃ES FINAIS}

A partir da análise que fizemos, chegamos à constatação de que as ações da obra se inter-relacionam sobrepondo uma à outra, o que pode drasticamente mudar a situação, isto é, as ações futuras, podem mudar a concepção das ações passadas, além disso, percebemos que, de uma forma ou de outra, a obra organiza essas ações de forma temporal, havendo uma relação entre ações passadas, presentes e possibilidades futuras.

Como essas ações se sobrepõem, não podemos analisar uma obra ou atribuir-lhe qualquer valor a partir de seus fragmentos, visto que partes da obra não representarão o real conteúdo dela. Porém conforme os estudos da Estética da Recepção, nada impede o leitor de perceber o passo a passo da construção da interpretação completa de uma obra.

Dessa forma, em relação ao nosso principal personagem objeto de análise, chegamos à conclusão que, embora em alguns momentos seja posto como um verdadeiro "ladrão de mulheres", um vilão, ao final nossa concepção sobre ele pode mudar drasticamente, isso porquê as ações ao sobreporem-se propiciam-nos essa interpretação, já que apesar do seu lado vilão, nessa passagem de tempo delimitada pelo conto é ele que está sofrendo com a ação de outro vilão, caracterizando nosso personagem como uma espécie de anti-herói. Mostrando que o leitor não deve ir a uma obra com uma concepção inicial, que poderá ser tida como dogmática, pois sabemos que no decorrer da narrativa essas concepções poderão ser quebradas ou mudadas.

Daí, concluímos que, além das ações da obra sobreporem-se, proporcionando a ela uma natureza de instabilidade ao longo de sua composição e ser de caráter perspectivístico, a obra pode assumir diferentes conclusões dependendo do ponto de vista assumido pelo leitor a partir de sua experiência de vida, o que, como já foi dito, implicará na sua atribuição de valor literário.

\section{REFERÊNCIAS}

BAKHTIN, Michail Mikhailovitch. Estética da criação verbal. Introdução e tradu-

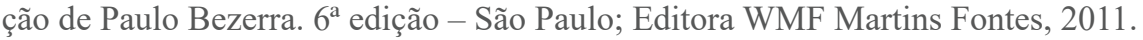

COMPAGNON, Antoine. O demônio da teoria: literatura e senso comum; tradução de Cleonice Paes Barreto Mourão, Consuelo Fortes Santiago $-2^{\mathrm{a}}$ ed. - Belo Horizonte: Editora UFMG, 2010.

CULLER, Jonathan. Teoria literária: uma introdução. Tradução Sandra Vasconcelos - São Paulo: Beca Produções Culturais Ltda. 1999.

ECO, Umberto. Obra aberta: formas e indeterminação nas poéticas contemporâneas. Tradução Giovanni Cutolo [et al.] - 10 ed. - São Paulo: Perspectiva, 2015.

FERRAREZI JUNIOR, Celso. Semântica para a educação básica. $1^{\mathrm{a}}$ ed. São Paulo; Parábola Editorial, 2008. 
ISER, Wolfgang. O ato da leitura: uma teoria do efeito estético - Vol. 1 e 2; tradução de Johannes Kretschmer - 34ª ed. - São Paulo: Editora 34, 1996.

JAUSS, Hans Robert. A história da literatura como provocação à teoria literária. Vol. 36. Tradução de Sérgio Tellaroli. São Paulo - SP: Editora Ática, 1994.

PROENÇA, Edyr. Nunca Mais. In: Vários autores. O corvo. Editora Empírio - São Paulo, 2015. Pg. 158-159.

PROENÇA, Edyr Augusto. Edyr Augusto Proença: Autor. Disponível em: <https:// www.boitempoeditorial.com.br/autor/edyr-augusto-proenca-19>. Acesso em: 24 de novembro de 2017

SCHOLLHAMMER, Karl Erik. Ficção brasileira contemporânea. Civilização Brasileira - Rio de Janeiro, 2009.

TODOROV, Tzvetan. Simbolismo e interpretação. Trad. Nídia Adan Bonatti - $1^{\text {a }}$ ed. - São Paulo: Editora Unesp, 2014.

ZILBERMAN, Regina. Fim do livro, fim dos leitores? Editora Senac - São Paulo, 2001. 